\title{
Homologous cloning, characterization and expression of a new halophyte phytochelatin synthase gene in Suaeda salsa*
}

\author{
CONG Ming (从明) $)^{1}$, ZHAO Jianmin (赵建民) ${ }^{1}$, LÜ Jiasen (吕家森) ${ }^{2}$, \\ REN Zhiming (任志明) $)^{2}$, WU Huifeng (吴惠丰) $)^{1, * *}$

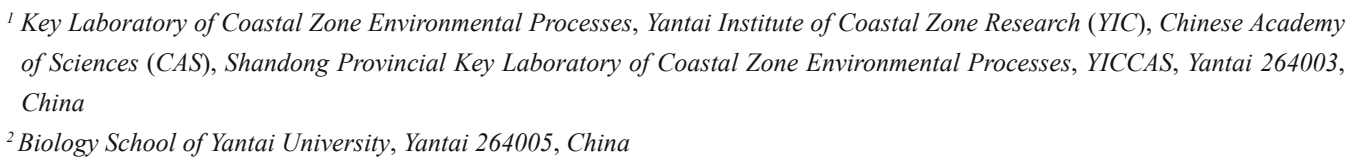

Received Jan. 6, 2015; accepted in principle Jun. 6, 2015; accepted for publication Aug. 6, 2015

(C) Chinese Society for Oceanology and Limnology, Science Press, and Springer-Verlag Berlin Heidelberg 2016

\begin{abstract}
The halophyte Suaeda salsa can grow in heavy metal-polluted areas along intertidal zones having high salinity. Since phytochelatins can effectively chelate heavy metals, it was hypothesized that $S$. salsa possessed a phytochelatin synthase (PCS) gene. In the present study, the cDNA of PCS was obtained from $S$. salsa (designated as SsPCS) using homologous cloning and the rapid amplification of cDNA ends (RACE). A sequence analysis revealed that $S S P C S$ consisted of 1916 bp nucleotides, encoding a polypeptide of 492 amino acids with one phytochelatin domain and one phytochelatin $\mathrm{C}$ domain. A similarity analysis suggested that SsPCS shared up to a 58.6\% identity with other PCS proteins and clustered with PCS proteins from eudicots. There was a new kind of metal ion sensor motif in its C-terminal domain. The SsPCS transcript was more highly expressed in elongated and fibered roots and stems $(P<0.05)$ than in leaves. Lead and mercury exposure significantly enhanced the mRNA expression of $\operatorname{Ss} P C S(P<0.05)$. To the best of our knowledge, SsPCS is the second PCS gene cloned from a halophyte, and it might contain a different metal sensing capability than the first $P C S$ from Thellungiella halophila. This study provided a new view of halophyte $P C S$ genes in heavy metal tolerance.
\end{abstract}

Keyword: Suaeda salsa; halophyte; phytochelatin synthase (PCS); homologous cloning; heavy metal; tissue distribution

\section{INTRODUCTION}

Plants have evolved many defense mechanisms to avoid adverse stimuli from the external environment. Non-essential heavy metals (e.g., lead, cadmium and mercury) and excessive essential heavy metals (e.g., zinc and copper) can have many deleterious effects on plants, such as chlorosis, necrosis, accelerated aging, and changes in ionome and hormonal status (Lequeux et al., 2010; Pandey and Singh, 2012). To detoxify non-essential or excessive essential heavy metals, high-affinity substances with abundant thiol groups, such as phytochelatins (PCs), can be used to chelate, sequestrate and compartmentalize heavy metals (Mendoza-Cózatl et al., 2006).

PCs are a series of peptides containing a landmark structure $(\gamma \text {-Glu-Cys })_{n}$-Gly $(n=2-11)$ that play principal roles in the detoxification of heavy metals, such as lead $(\mathrm{Pb})$, mercury $(\mathrm{Hg})$, copper $(\mathrm{Cu})$, zinc ( $\mathrm{Zn})$ and cadmium (Cd) (Tsuji et al., 2002; Ramos et al., 2008). However, PCs are not synthesized directly but by transferring the glutamylcysteine dipeptide moiety of glutathione to another glutathione until an oligomer chain is formed, which contains 2 to 11 $\gamma$-Glu-Cys monomers (Grill et al., 1989). This reaction is catalyzed by the phytochelatin synthase gene (PCS) that has been widely found in many kinds of organisms (Cobbett, 1999; Brulle et al., 2008). To our knowledge, the PCS gene was isolated from the halophyte

\footnotetext{
* Supported by the 100 Talents Program of the Chinese Academy of Sciences and the Key Technology R\&D Program of Shandong Province (No. 2012GGA06032)

** Corresponding author: hfwu@yic.ac.cn
} 
Thellungiella halophila, a model plant for salt tolerance research (Taji et al., 2010). However, there are no reports from other salt-tolerant plants.

Suaeda salsa is a native halophyte in the intertidal zones around the Bohai Sea in North China that can grow in soil containing up to $3 \%$ soluble salt. Recent studies reveal that halophytes are preferable candidates for the phytoremediation of heavy metalpolluted saline soil, owing to their more efficient capabilities to deal with heavy metals than saltsensitive plants (Manousaki and Kalogerakis, 2011). $S$. salsa has a remarkable ability to accumulate heavy metals, such as $\mathrm{Pb}, \mathrm{Zn}, \mathrm{Cu}, \mathrm{Cd}$ and $\mathrm{Hg}$ (Zhu et al., 2005; Wu et al., 2012). Accordingly, S. salsa may be an ideal plant to indicate heavy metal contamination in saline soil around the Bohai Sea. Since PCs can effectively chelate heavy metals, it was hypothesized that $S$. salsa contained a PCS-like gene encoding a PCS, which catalyzed the synthesis of PCs.

In previous studies, several heavy metals were reported to be typical contaminants around the Bohai coastal area, including $\mathrm{Cd}, \mathrm{Pb}$, arsenic (As), $\mathrm{Hg}$ and Zn (Zhang, 2001; Mao et al., 2009). Among them, the sediment concentrations of $\mathrm{Pb}, \mathrm{Zn}$ and $\mathrm{Hg}$ could reach 30,150 , and $66 \mathrm{mg} / \mathrm{kg}$, respectively. Such heavy metal pollution was reported to be caused by the effluents from many smelting and electroplating factories located around the Bohai Coast (Mao et al., 2009). These high heavy metal concentrations might be prominent dangers to the intertidal plants, and PCs would be synthesized under such exposure.

In this study, the PCS gene in S. salsa (SsPCS) was obtained using a homologous cloning approach. A sequence analysis and multiple sequence alignment were performed to predict its potential functions based on those of other known PCS genes. Expression patterns under exposure to several heavy metals $(\mathrm{Pb}$, $\mathrm{Zn}$ and $\mathrm{Hg}$ ) at environmentally relevant concentrations were described and analyzed to determine the regulatory pattern of SsPCS. Additionally, the distribution of SSPCS in different tissues over time was investigated. To our knowledge, this is the second $P C S$ gene that has been identified and characterized in a halophyte, and it provides a new facet to complement that of the first PCS from T. halophila.

\section{MATERIAL AND METHOD}

\subsection{Plants and treatment}

The black seeds of $S$. salsa were sampled from the Huanghe (Yellow) River Delta $\left(37^{\circ} 40^{\prime}-38^{\circ} 10^{\prime} \mathrm{N}\right.$, $\left.118^{\circ} 41^{\prime}-119^{\circ} 16^{\prime} \mathrm{E}\right)$ in November 2011 and stored at $4^{\circ} \mathrm{C}$. Before cultivation, the seeds were sterilized by immersion in $0.5 \% \mathrm{HgCl}_{2}$ for $10 \mathrm{~min}$, and then washed in double-distilled water three times. Seeds were sown in the sand in pots with $20-\mathrm{cm}$ diameters. Four pots were used in the experiment, with one control and three heavy metal-exposed groups. After germination, the seeds were irrigated with Hoagland's nutrient solution for $60 \mathrm{~d}$. Then, the plantlets in the three exposed groups were independently fertilized with Hoagland's nutrient solution containing $20 \mu \mathrm{g} / \mathrm{L}$ lead $\left(\mathrm{Pb}\left(\mathrm{NO}_{3}\right)_{2}\right), 100 \mu \mathrm{g} / \mathrm{L}$ zinc $\left(\mathrm{ZnCl}_{2}\right)$ and $20 \mu \mathrm{g} / \mathrm{L}$ $\mathrm{Hg}\left(\mathrm{HgCl}_{2}\right)$. All of the concentrations used in the study were reported to be environmentally relevant in areas near the Huanghe River Delta (Zhou and Yan, 1997; Zhang, 2001). After exposure for $30 \mathrm{~d}$, five plantlets were randomly harvested from the control and heavy metal-exposed groups. Leaves and tender branches were picked to study the expression profiles of $S S P C S$ under exposure to different heavy metals. At the same time, leaves, stems and roots from $S$. salsa plantlets $(n=5)$ in the control groups were collected twice $(\mathrm{T} 1=45 \mathrm{~d}$ and $\mathrm{T} 2=60 \mathrm{~d}$ postgermination) to investigate the tissue distribution of $S s P C S$. All of the samples were stored at $-80^{\circ} \mathrm{C}$ prior to further investigation.

\subsection{Homologous cloning of the full-length cDNA of SsPCS}

Tissue samples of $S$. salsa were ground in liquid nitrogen. RNA extraction and synthesis of the first strand cDNA were carried out as described previously (Cong et al., 2013). Based on the conserved motifs found in PCS proteins collected from the National Center for Biotechnology Information, degenerate primers were designed using the iCODEHOP program (Boyce et al., 2009). A primer pair, forward (F1: GACCCCGGCCGNAARTGGAARG) and reverse (R1: GCACCCAGTGAGGAGGRTAYTTRAA), with a relatively low degree of degeneracy was used during the first degenerate $\mathrm{PCR}$ reaction. The program was as follows: $94^{\circ} \mathrm{C}$ for $5 \mathrm{~min}, 35$ cycles of $94^{\circ} \mathrm{C}$ for $5 \mathrm{~s}$ and 67 to $61^{\circ} \mathrm{C}$ for $2 \mathrm{~min}$, followed by $72^{\circ} \mathrm{C}$ for $10 \mathrm{~min}$. The final products having the expected sizes were ligated into the pMD18-T Simple Vector, and five positive clones were sequenced in both directions.

Based on the sequences of the DNA fragment obtained by degenerate PCR, 5' and $3^{\prime}$ rapid amplification of cDNA ends (RACE) was performed to produce the full-length cDNA of SsPCS. Briefly, oligo dG (GGCCACGCGTCGACTAGTACG ${ }_{10}$ ) and 
gene-specific primer R2 (R2: TAACCACCAATCGGAGAAAA) were used to amplify the 5 ' end of $S s P C S$. Oligo dT (GGCCACGCGTCGACTAGTACT ${ }_{17}$ ) and gene-specific primer F2 (F2: ATGCCTAGCTCGCTGTAATG) were used to produce the $3^{\prime}$ end of SsPCS. The PCR products were cloned and sequenced as described above. The resulting sequences were verified and a cluster analysis was performed using MEGA version 4 (Tamura et al., 2007).

\subsection{Sequence analysis, multiple sequence alignment and phylogenetic tree of PCS}

Sequences of the SsPCS cDNA and its deduced amino acids were analyzed using the BLAST algorithm (http://www.ncbi.nlm.nih.gov/blast) and the Expert Protein Analysis System (http://www.expasy.org/). The protein domain was predicted using the Simple Modular Architecture Research Tool (SMART) version 4.0 (http://www.smart.emblheidelberg.de/). The percentages of similarity and identity between SsPCS-domains and the corresponding domains in other PCS proteins were calculated by the Identity and Similarity Analysis program (http://www.biosoft.net/ sms/index.html). Similarities of nucleotides and proteins were determined using the BLAST algorithm at the National Center for Biotechnology Information (Altschul et al., 1997). Twenty-two PCS protein sequences were used to perform multiple alignments using the Clustal W Multiple Alignment program (http://www.ebi.ac.uk/clustalw/). A phylogenetic tree was constructed based on the amino acid sequence alignments of the conserved $\mathrm{N}$-terminal domain of the PCS proteins by the neighbor-joining method, with 1000 replications in the bootstrap test, using the MEGA program (version 4.0).

\subsection{Real-time PCR analysis of SsPCS mRNA expression in different tissues and after exposure to different heavy metals}

Two SsPCS gene-specific primers (F3: CTCGCTGTAATGGAGCAGAAGT and R3: GGTAACCACCAATCGGAGAAAA) were used to amplify a product of $177 \mathrm{bp}$, and the PCR product was sequenced to verify the specificity of the qRTPCR. Two $S$. salsa actin primers (AF: ATCCGCAAAGATTACATACCATA and AR: TTGTTCACCGAAAGTGCTTCT) were used to amplify a 254-bp fragment as an internal control used to calibrate the cDNA template for the corresponding samples. DEPC-water was used as a negative control to replace the cDNA template in qRT-PCR.

Real-time PCR amplification was performed in an ABI 7500 fast Real-time Thermal Cycler according to the manual (Applied Biosystems). A dissociation curve analysis of the amplification products was performed at the end of each PCR to confirm that only one product was amplified and detected. Data were analyzed automatically using ABI 7500 SDS software (Applied Biosystems). The Ct values for SsPCS and the control actin were assayed for each sample. The comparative CT method was used to analyze the expression level of SsPCS (Livak and Schmittgen, 2001). All data were given in terms of mean \pm S.D. $(n=5)$. The final results of the gene expression were subjected to one-way ANOVA followed by least significant difference (LSD) analysis, and statistical significance was defined as $P<0.05$.

\section{RESULT}

\subsection{Gene cloning, sequencing and analysis of the full-length SsPCS}

After degenerate PCR, a 417-bp-length DNA encoding the partial protein sequence of PCS was amplified. Based on the cloned sequence, two genespecific primers (F2 and R2) were designed to clone the full length of SsPCS, and two fragments of $477 \mathrm{bp}$ and 1296 bp were amplified by 3' and 5' RACE, respectively. The whole cDNA sequence of $S S P C S$ was obtained by overlapping the two fragments cloned by $3^{\prime}$ and 5' RACE with the fragment from degenerate PCR. The complete sequence of SsPCS was deposited in GenBank (Accession No. KC109195). The whole SsPCS cDNA sequence consisted of a $5^{\prime}$ untranslated region of $131 \mathrm{bp}$, a $3^{\prime}$ untranslated region of $306 \mathrm{bp}$ and an open reading frame of $1479 \mathrm{bp}$ encoding a polypeptide of 492 amino acids with an estimated molecular mass of $54.52 \mathrm{kD}$. Two domains were predicted in the deduced amino acid sequence; one was a PC domain (positioned from 8 to 218 aa with an E-value of 3.84e84) at the N-terminus and the other was PC C (positioned from 222 to 481 aa with an E-value of 3.77e-74) at the C-terminus of the SsPCS protein (Fig.1). A tertiary structure prediction revealed that the SsPCS protein was a typical papain-like enzyme in $\mathrm{PC}$ synthesis and that $\mathrm{Cys}^{57}$, His ${ }^{163}$ and $\mathrm{Asp}^{181}$ constituted the catalytic sites of SsPCS. According to the modeled tertiary structure, there was a $\mathrm{Thr}^{49}$ near the catalytic site that might form a second substratebinding site with another $\operatorname{Arg}^{184}$ residue. 


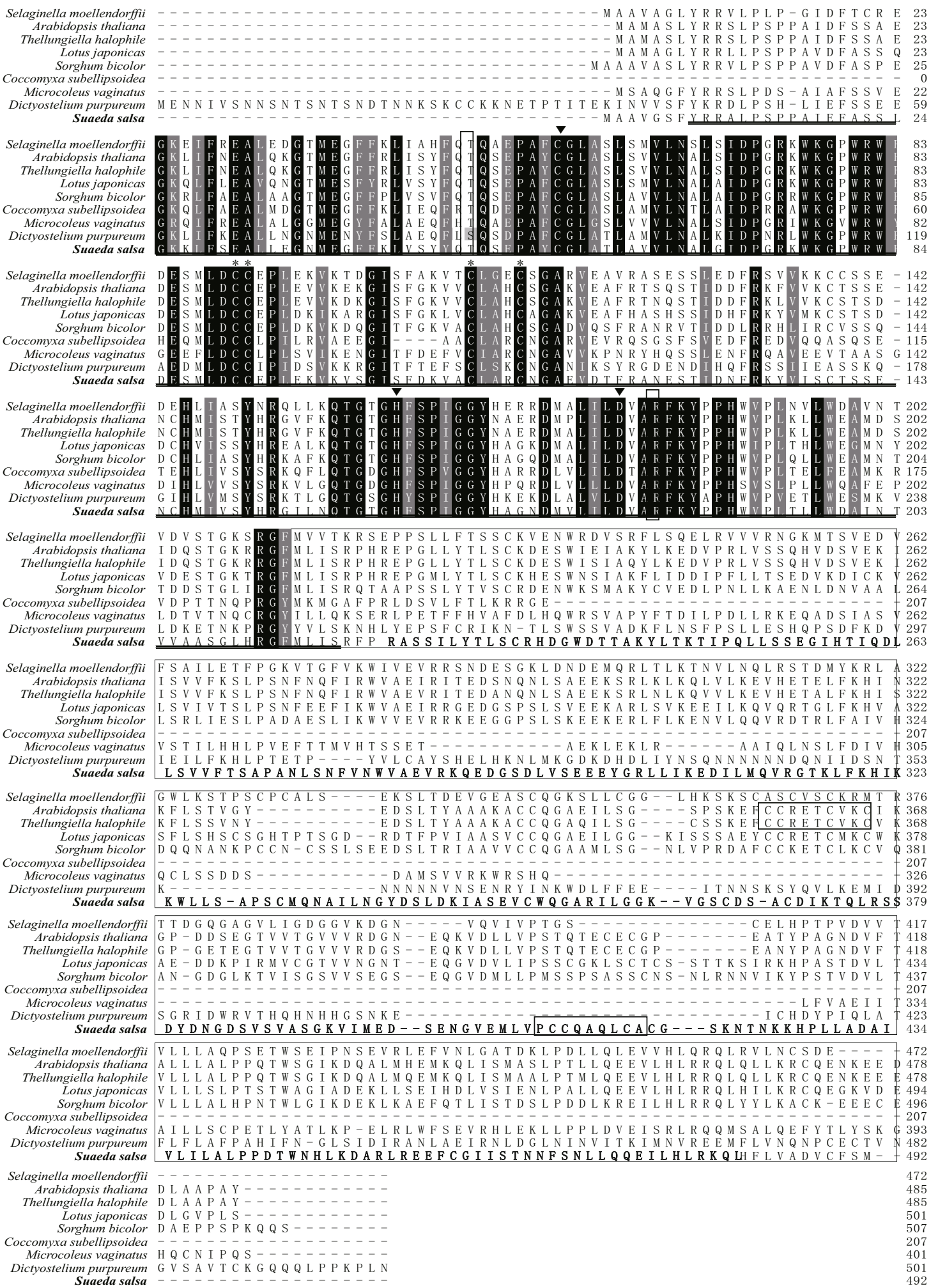

Fig.1 Alignment of SsPCS and eight other PCS protein sequences

Identical residues are darkly shaded and similar residues are shaded in gray. The conserved catalytic Cys-His-Asp triad is indicated by the inverted triangle " $\boldsymbol{\nabla}$ ". The other conserved Cys residues are marked by an asterisk "*". Two important residues that might constitute a second substrate-binding site (Thr ${ }^{49}$ and $\mathrm{Arg}^{184}$ in SsPCS) were framed in all of the selected sequences. The two predicted domains phytochelatin, which is double-underlined and phytochelatin C, which is in bold, are indicated separately. The "ion sensor" motif CCXXXXCXC of SsPCS, Arabidopsis Thaliana PCS and Thellungiella halophila PCS are framed in the C-terminal domain. The eight selected PCS proteins are Selaginella moellendorffii (XP_002976553), A. thaliana (ABW98498), T. halophila (BAJ34584), Lotus japonicus (Q2TSC7), Sorghum bicolor (XP 002454970), Coccomyxa subellipsoidea (EIE19118), Microcoleus vaginatus (WP_006632494) and Dictyostelium purpureum (XP_003285073). 


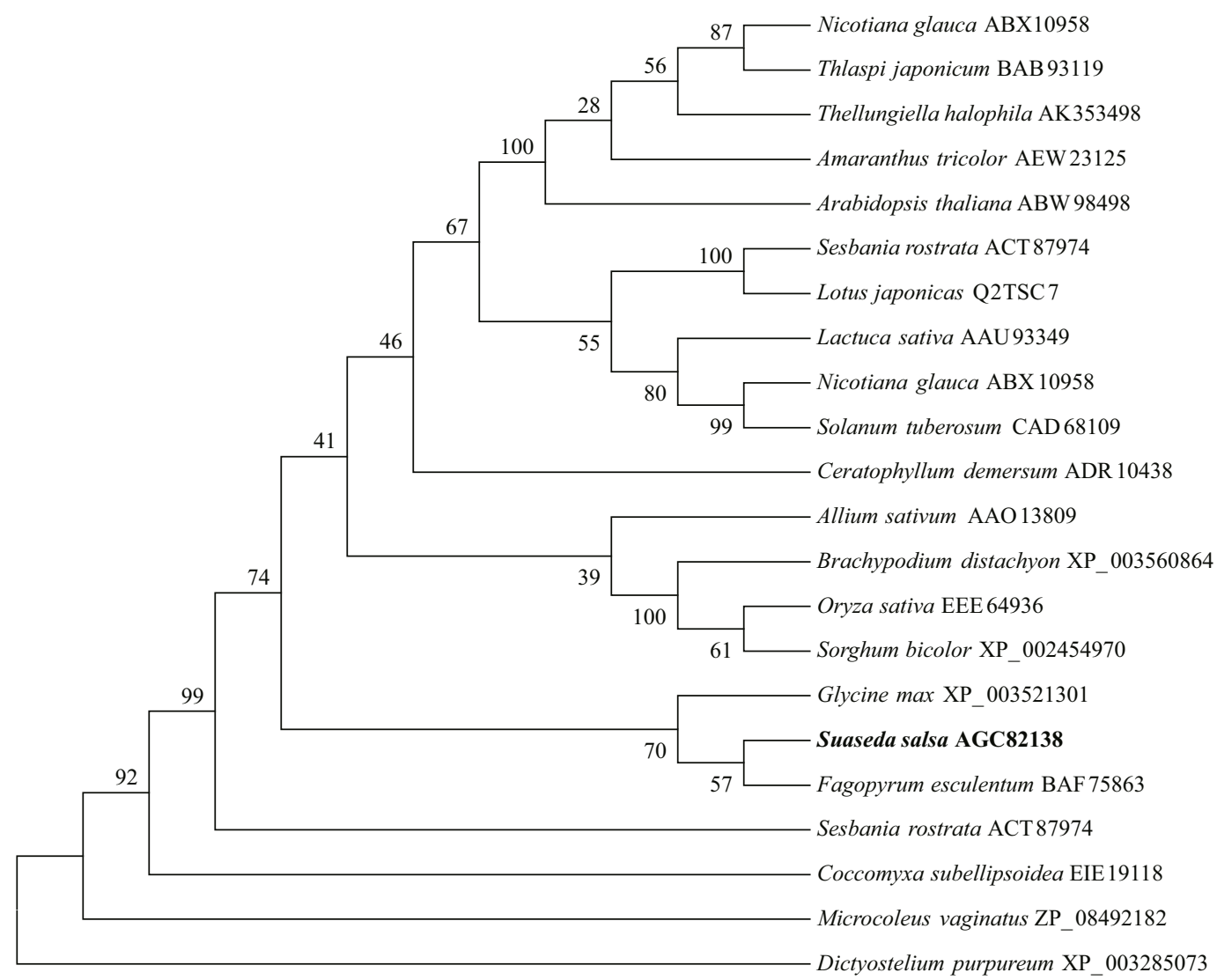

Fig.2 The phylogenetic tree of the conserved N-terminal domain of the PCS proteins

One thousand bootstrap trials were performed using the neighbor-joining algorithm with the Mega program version 4.0. The number associated with each branch is the local bootstrap probability, which indicates the confidence.

\subsection{Multiple sequence alignments and a phylogenetic analysis}

The deduced amino acid sequence of the SsPCS protein (AGC82138) showed a considerable identity with 21 other PCS proteins from monocots (Brachypodium distachyon, Oryza sativa, Sorghum bicolor and Allium sativum), eudicots (Nicotiana glauca, Solanum tuberosum, Sesbania rostrata, Lactuca sativa, Amaranthus tricolor, Lotus japonicus, Amaranthus tricolor, Arabidopsis thaliana, Noccaea caerulescens, Thlaspi japonicum, T. halophila, Ceratophyllum demersum and Glycine max), clubmosses (Selaginella moellendorffii), green algae (Coccomyxa cubellipsoidea), cyanobacteria (Microcoleus vaginatus) and cellular slime molds (Dictyostelium purpureum). Five cysteine residues $\left(\mathrm{Cys}^{57}, \mathrm{Cys}^{91}, \mathrm{Cys}^{92}, \mathrm{Cys}^{110}\right.$ and Cys $\left.{ }^{114}\right)$ in SsPCS were found to be conserved in all of the selected PCS protein sequences (Fig.2). The identities between SsPCS and other PCS proteins reached up to $58.6 \%$ according to the un-rooted phylogenetic tree constructed by the neighbor-joining method. The phylogenetic analysis showed that SsPCS shared different identities with PCS proteins from two Caryophyllales relatives, $58.6 \%$ to Fagopyrum esculentum (BAF75863) and only 50.4\% to Amaranthus tricolor (AEW23125). According to the phylogenetic tree, SsPCS first formed a sub-branch with the F. esculentum PCS, and then clustered with the G. max PCS. However, the sub-branch of SsPCS and $F$. esculentum PCS diverged from the A. tricolor PCS, which formed a sub-branch with another halophyte, T. halophila PCS.

\subsection{Tissue distribution of SsPCS}

An analysis of the tissue distribution showed that SsPCS was expressed in all of the tissues of nonstressed $S$. salsa, including the root, stem and leaf. No significant differences were detected among these tissues at $45 \mathrm{~d}$ post-germination. However, when the plantlets were collected at $60 \mathrm{~d}$, the $S s P C S$ expression level was significantly higher in $\operatorname{root}(P<0.01)$ and stem $(P<0.05)$ than in leaf (Fig.4). Overall, more SsPCS transcripts were expressed in roots and stems at $60 \mathrm{~d}$ compared with at $45 \mathrm{~d}(P<0.05)$. 


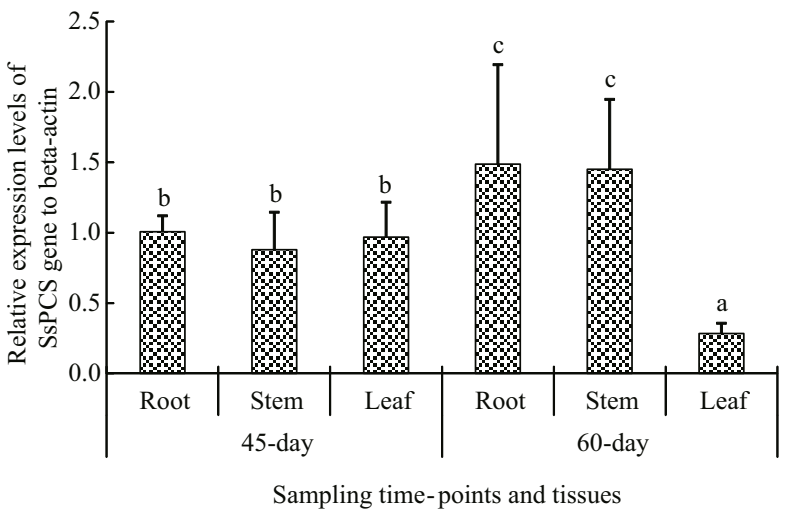

Fig.3 Tissue distribution of SsPCS in root, stem and leaf

The expression levels are expressed as ratios to the expression of $\beta$-actin. Different letters denote significant differences $(P<0.05)$.

\subsection{Quantitative analysis of SsPCS mRNA expression after heavy metal exposure}

An analysis using quantitative real-time PCR revealed that all of the tested heavy metals, including $\mathrm{Pb}, \mathrm{Zn}$, and $\mathrm{Hg}$, could induce SsPCS mRNA expression. However, significant increments of $S s P C S$ transcripts were detected in the $\mathrm{Pb}$ - (3.2-fold, $P<0.05)$ and $\mathrm{Hg}$ - $(2.8$-fold, $P<0.05)$ exposed groups compared with the control group. There were no significant differences between the Zn-exposed (1.2fold) and control groups (Fig.5).

\section{DISCUSSION}

S. salsa is a halophyte found near the Bohai Sea in North China. In a previous study, S. salsa was determined to have the capability to tolerate heavy metal contamination without significant changes in biomass or height (Liu et al., 2011). Given that PC is hypothesized to be the main factor needed to detoxify heavy metals in plants (Inouhe et al., 2000), it could be synthesized in $S$. salsa as well. The successful cloning of the $S s P C S$ gene will contribute to a better understanding of the heavy metal tolerance potential of $S$. salsa and may aid in the future phytoremediation of the coastline.

In the present study, SsPCS was obtained from the leaves of $S$. salsa using homologous cloning. It contained an open reading frame of 492 amino acids without a signal peptide. According to the structure prediction of the SsPCS protein, two conserved domains were found, a PCS domain (N-terminus) and PC C domain (C-terminus). The PCS domain contains a papain fold and belongs to the papain-like cysteine proteases superfamily. A multiple sequence alignment revealed that such a domain was highly conserved in

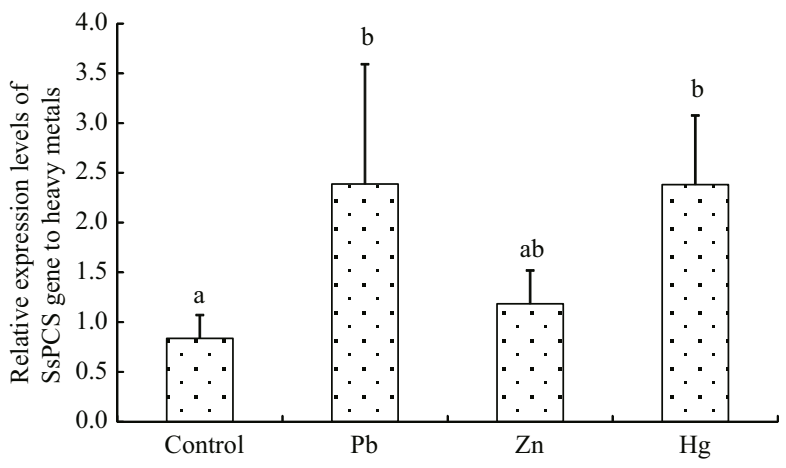

Fig.4 Temporal profiles of SsPCS mRNA after exposure to $\mathrm{Pb}, \mathrm{Zn}$ and $\mathrm{Hg}$ for $30 \mathrm{~d}$

The expression levels are expressed as ratios to the expression of $\beta$-actin. Different letters denote significant differences $(P<0.05)$.

most PCS proteins. There were several conserved residues in the $\mathrm{N}$-terminal domain that might play crucial roles in the catalytic activity of the PCS protein. $\mathrm{Cys}^{56}{ }^{5} \mathrm{His}^{162}$ and $\mathrm{Asp}^{180}$ of the papain fold in the $A$. thaliana PCS constitute the catalytic triad (Rea, 2006), and the corresponding amino acid residues in the SsPCS protein were $\mathrm{Cys}^{57}$, His ${ }^{163}$ and $\mathrm{Asp}^{181}$. Studies on limited proteolysis and amino acid mutation suggested that the PCS domain was enough to allow the catalysis of deglycination of a GSH donor molecule to $\gamma$-Glu-Cys (Vatamaniuk et al., 1999; Ruotolo et al., 2004). Thus, $\mathrm{Cys}^{57}$, His ${ }^{163}$ and Asp ${ }^{181}$ constitute the catalytic core responsible for the enzyme activity of SsPCS. In addition to the three residues, $\mathrm{Thr}^{49}$ and $\operatorname{Arg}^{184}$ might also be important for efficient catalysis by SsPCS. The multiple sequence alignment revealed that $\mathrm{Thr}^{49}$ in SsPCS was conserved in most eukaryote PCS proteins, except that from D. purpureum, and $\operatorname{Arg}^{184}$ was found in all of the selected PCS proteins. These two highly conserved residues are important for PCS function. In Arabidopsis, the enzyme activity of PCS1 decreased following $\mathrm{Thr}^{49}$ phosphorylation (Wang et al., 2009). $\operatorname{Arg}^{183}$ of A. thaliana PCS1 (equivalent to $\mathrm{Arg}^{184}$ of SsPCS) is identified in the proximity of $\mathrm{Thr}^{49}$ in the three-dimensional structure. They interact and create a cavity that constructs a second binding site for the GSH to react with $\gamma \mathrm{EC}$ (Wang et al., 2009). Accordingly, it could be postulated that $\mathrm{Thr}^{49}$ and $\mathrm{Arg}^{184}$ were critical to the catalytic activity of SsPCS as well.

As for the domain at the C-terminus of the SsPCS protein, $\mathrm{PC} \mathrm{C}$ is found to be rich in cysteine and acts as an auxiliary element in plant PCSs. Although the sequence alignment shows more variability in this domain than that at the N-terminus, a functional analysis suggests that the $\mathrm{C}$-terminal domain can act 
as metallothionein or metallochaperone to help distinguish heavy metals and activate the acylation reaction of $\gamma$-Glu-Cys (Rea, 2006; Romanyuk et al., 2006). In A. thaliana, there are 10 Cys residues in the $\mathrm{C}$-terminus domain and each Cys residue functions as a free-SH residue to bring metal ions into a closer position in the catalytic domain (Vestergaard et al., 2008). A landmark motif, CCXXXCXXC, consisting of four Cys residues in the $\mathrm{PC} \mathrm{C}$ domain of the A. thaliana PCS, is regarded as an ion sensor activated directly by heavy metals (Rea, 2006). In contrast to this, there are 11 Cys residues in the PC C domain of the SsPCS protein and the "ion sensor" motif was expressed as CCXXXXCXC, which was different from that of the $A$. thaliana PCS. Although there are also 11 Cys residues in the T. halophila PCS, the ion sensor motif that was expressed was the same as that in the A. thaliana PCS. Different structures of ion sensors might result in different ion sensing abilities/ specificity between SsPCS and the T. halophila PCS. Further work will be designed to investigate their different capabilities in ion sensing.

As a member of Caryophyllales, $S$. sals $a$ is closely related to A. tricolor and $F$. esculentum. In the phylogenetic tree based on the alignment of amino acid sequences of PCSs, SsPCS clustered with the $F$. esculentum PCS (AEW23125) in the same subgroup but showed a longer phylogenetic distance with the A.tricolor PCS (BAF75863). Therefore, the phylogenetic analysis of SsPCS was not in good agreement with the position of $S$. salsa in the plant kingdom. There may be a divergence in the molecular phylogenetics of PCS genes, and SsPCS was probably derived from a common ancestor with the eudicotic PCS family of proteins.

The gene expression levels of $S s P C S$ were detected using a quantitative real-time PCR analysis according to $\mathrm{Wu}$ et al. (2012). Several house-keeping genes were selected for quantitative references, and a GeNorm analysis revealed that the familiar actin gene was suitable for normalization in this study. The tissue distribution revealed that $S S P C S$ was a constitutively expressed gene that was expressed in all of the tested tissues. However, with the development of vascular elements in the tender stems and roots, a higher expression level of $S S P C S$ was found in the fibered tissues than in the carnose leaves. A study of Brassica juncea suggested that PCS was mostly expressed in vascular tissues, including petioles, internodes and special trichomes (Heiss et al., 2003). In the present study, the plantlets had $\sim 4$ to 6 leaves by the $45^{\text {th }} \mathrm{d}$ and
10 to 12 leaves with little lateral branches by the $60^{\text {th }} \mathrm{d}$ post-germination. During the early developmental stage, no significant differences in $S s P C S$ expression in any of the tissues could account for the high carnification with the low degree of fibrosis in the $S$. salsa plantlets. With the development of the vascular contents in stems and roots, more SsPCS transcripts were detected in such tissues but they were only detected in the leaves at later stages.

The exposure to different heavy metals indicated that $20 \mu \mathrm{g} / \mathrm{L}$ of $\mathrm{Pb}^{2+}$ and $20 \mu \mathrm{g} / \mathrm{L}$ of $\mathrm{Hg}^{2+}$ could significantly enhance the expression of SsPCS. However, no significant difference in SsPCS expression was observed in $100 \mu \mathrm{g} / \mathrm{L}$ of $\mathrm{Zn}^{2+}$-exposed $S$. salsa samples compared with that of the control group. This may indicate that zinc is an essential element and acts as a non-activator of $S s P C S$ expression. The differential induction of PCS expression by zinc has been reported in other plants. $\mathrm{Zn}^{2+}$ spurred more activation than the other heavy metals on PCS expression in the marine green alga Dunaliella tertiolecta (Hirata et al., 2001). However, there was also an opposite case. Nguyen-Derocheet al. (2012) studied the effects of zinc supplementation on PCS gene expression in four kinds of marine diatoms. They found that zinc induced PCS expression in Nitzschia palea but there were no other significant differences compared with the control group. In addition, no PCS gene expression was detected in the other three kinds of diatoms, although PCS genes were identified in all of them. Zinc appeared not to be an expression activator of diatom PCS genes. As nonessential heavy metals, $\mathrm{Pb}$ and $\mathrm{Hg}$ are more toxic to plants and a low concentration of $20 \mu \mathrm{g} / \mathrm{L}$ could induce the significant expression of $S s P C S$. In L.japonicus, $\mathrm{Pb}$ and $\mathrm{Hg}$ significantly but differentially induced the PCS1 and PCS3 genes, and such a variance was ascribed to the differences in the C-terminal domains of the two PCS proteins (Ramos et al., 2008). In a similar manner, the different responses of $S s P C S$ to $\mathrm{Pb}, \mathrm{Zn}$ and $\mathrm{Hg}$ might mirror the metal activation patterns of the SsPCS C-terminal domain and metal accumulation in plants.

To our knowledge, SsPCS is the second gene encoding PCS cloned from a halophyte. The first one, T. halophila PCS, was found using a large-scale analysis of enriched cDNAs from T. halophila, a related halophyte model to Arabidopsis (Taji et al., 2010). Presently, no detailed study has described the function of the $T$. Halophila PCS in saline environments. A recent study revealed that 
supplementation with low levels of salt reduced the adverse effects of heavy metal exposure on $A$. thaliana in oxidative damage and growth inhibition, and increased heavy metal accumulation, with the aid of an elevated PC level (Xu et al., 2010). PC may have played important roles in heavy metal tolerance and accumulation in plants, especially in the coastal environment. As a halophyte, S. salsa was shown previously to have a strong heavy metal tolerance (Zhu et al., 2005; Wu et al., 2012). Our current study revealed that SsPCS had the typical PCS protein structure that may catalyze the synthesis of PC and heavy metals, especially $\mathrm{Pb}$ and $\mathrm{Hg}$, which could effectively induce SsPCS mRNA expression. SsPCS might play an important role in detoxifying heavy metals, especially $\mathrm{Pb}$ and $\mathrm{Hg}$. Based on the predicted functions and expression profiles of SsPCS upon heavy metal exposures, we determined its possible mechanism in heavy metal detoxification. Heavy metals were first detected by the ion sensor motif with the aid of Cys residues in the PC C domain of the SsPCS protein, which then helped to bring heavy metal ions close to the catalytic center of the PCS domain, triggering PC synthesis. Additionally, different heavy metals exerted different capabilities for inducing the synthesis of PCS. Since there was no signal peptide predicted in SsPCS, the synthesis of PCs may have taken place in the vascular tissues, such as roots and stems. Induced by the heavy metals, a series of PCs with different numbers of $\gamma$-Glu-Cys monomers would be successfully produced by $S s P C S$ and play chelating roles by forming steady thiol-metal complexes to alleviate the toxic effects of metals invading normal cells. Gawel et al. (1996) first reported that the concentration of PCs could be used as an indicator of declining soil pollution by heavy metals. Since gene variations precede those of protein metabolism, and PCS genes could significantly activate their transcription levels due to certain kinds of heavy metals (Manier et al., 2012; Ahmad and Gupta, 2013), the detection of mRNA regulatory trends for inducible $P C S$ genes will give us an early environmental warning for heavy metal pollution. Therefore, relative expression levels of PCS transcripts could also be used as important biomarkers to indicate environmental pollution. Similarly, SsPCS was found to be constitutively expressed in S. Salsa but it can be significantly induced by $\mathrm{Pb}$ and $\mathrm{Hg}$, which implied that SsPCS could be used as a biomarker to indicate special kinds of heavy metals, especially $\mathrm{Pb}$ and $\mathrm{Hg}$ in coastal environments.

\section{CONCLUSION}

A complete length of $P C S$ cDNA was obtained by homologous cloning from $S$. salsa. In the PCS sequence, several highly conserved residues were found, including $\mathrm{Cys}^{57}, \mathrm{His}^{163}$ and $\mathrm{Asp}^{181}$ in the catalytic core and $\mathrm{Thr}^{49}$ together with $\mathrm{Arg}^{184}$ near the core, which would ensure the efficient catalysis of PC synthesis in $S$. salsa. Considering the landmark structure of the C-terminal domain of SsPCS, more Cys residues and a different arrangement of Cys residues in the ion sensor might lead to further investigation of the differences in metal requirements/ responses between the A. thaliana PCS and SsPCS. Among the tested heavy metals, $\mathrm{Pb}$ and $\mathrm{Hg}$ could significantly activate SsPCS expression rather than zinc. SSPCS is expressed constitutively but could be regulated at the transcriptional level during different developmental stages or under heavy metal stimuli. Therefore, our present work provides a new perspective on the mechanism of heavy metal tolerance.

\section{References}

Ahmad M A, Gupta M. 2013. Exposure of Brassica juncea (L) to arsenic species in hydroponic medium: comparative analysis in accumulation and biochemical and transcriptional alterations. Environ. Sci. Pollut. Res., 20(11): 8 141-8 150, http://dx.doi.org/10.1007/s11356013-1632-y.

Altschul S F, Madden T L, Schäffer A A, Zhang J H, Zhang Z, Miller W, Lipman D J. 1997. Gapped BLAST and PSIBLAST: a new generation of protein database search programs. Nucleic Acids Res., 25(17): 3 389-3 402, http:// dx.doi.org/10.1093/nar/25.17.3389.

Boyce R, Chilana P, Rose T M. 2009. iCODEHOP: a new interactive program for designing COnsensus-DEgenerate hybrid oligonucleotide primers from multiply aligned protein sequences. Nucleic Acids Res., 37(S2): W222-W228, http://dx.doi.org/10.1093/nar/gkp379.

Brulle F, Cocquerelle C, Wamalah A N, Morgan A J, Kille P, Leprêtre A, Vandenbulcke F. 2008. cDNA cloning and expression analysis of Eisenia fetida (Annelida: Oligochaeta) phytochelatin synthase under cadmium exposure. Ecotoxicol. Environ. Safety, 71(1): 47-55, http://dx.doi.org/10.1016/j.ecoenv.2007.10.032.

Cobbett C S. 1999. A family of phytochelatin synthase genes from plant, fungal and animal species. Trends in Plant Science, 4(9): 335-337, http://dx.doi.org/10.1016/S13601385(99)01465-X.

Cong M, Lv J S, Liu X L, Zhao J M, Wu H F. 2013. Gene expression responses in Suaeda salsa after cadmium exposure. Springer Plus, 2(1): 232, http://dx.doi.org/10. 1186/2193-1801-2-232. 
Gawel J E, Ahner B A, Friedland A J, Morel F M M. 1996. Role for heavy metals in forest decline indicated by phytochelatin measurements. Nature, 381(6577): 64-65, http://dx.doi.org/10.1038/381064a0.

Grill E, Löffler S, Winnacker E L, Zenk M H. 1989. Phytochelatins, the heavy-metal-binding peptides of plants, are synthesized from glutathione by a specific $\gamma$-glutamylcysteine dipeptidyl transpeptidase (phytochelatin synthase). Proc. Natl. Acad. Sci. USA, 86(18): 6 838-6 842, http://www.ncbi.nlm.nih.gov/pubmed/ 16594069.

Heiss S, Wachter A, Bogs J, Cobbett C, Rausch T. 2003. Phytochelatin synthase (PCS) protein is induced in Brassica juncea leaves after prolonged $\mathrm{Cd}$ exposure. $J$. Exp. Bot., 54(389): 1 833-1 839, http://www.ncbi.nlm.nih. gov/pubmed/12815036.

Hirata K, Tsujimoto Y, Namba T, Ohta T, Hirayanagi N, Miyasaka H, Zenk M H, Miyamoto K. 2001. Strong induction of phytochelatin synthesis by zinc in marine green alga, Dunaliella tertiolecta. J. Biosci. Bioeng., 92(1): 24-29, http://dx.doi.org/10.1016/S1389-1723(01)80193-6.

Inouhe M, Ito R, Ito S, Sasada N, Tohoyama H, Joho M. 2000. Azuki bean cells are hypersensitive to cadmium and do not synthesize phytochelatins. Plant Physiology, 123(3): 1 029-1 036, http://dx.doi.org/10.1104/pp.123.3.1029.

Lequeux H, Hermans C, Lutts S, Verbruggen N. 2010. Response to copper excess in Arabidopsis thaliana: impact on the root system architecture, hormone distribution, lignin accumulation and mineral profile. Plant Physiol. Biochem., 48(6): 673-682, http://dx.doi. org/10.1016/j.plaphy.2010.05.005.

Liu X L, Yang C Y, Zhang L B, Li L Z, Liu S J, Yu J B, You L P, Zhou D, Xia C H, Zhao J M, Wu H F. 2011. Metabolic profiling of cadmium-induced effects in one pioneer intertidal halophyte Suaeda salsa by NMR-based metabolomics. Ecotoxicology, 20(6): 1 422-1 431, http:// dx.doi.org/10.1007/s10646-011-0699-9.

Livak K J, Schmittgen T D. 2001. Analysis of relative gene expression data using real-time quantitative PCR and the $2^{-\Delta \Delta C T}$ method. Methods, 25(4): 402-408, http://dx.doi. org/10.1006/meth.2001.1262.

Manier N, Brulle F, Le Curieux F, Vandenbulcke F, Deram A. 2012. Biomarker measurements in Trifolium repens and Eisenia fetida to assess the toxicity of soil contaminated with landfill leachate: a microcosm study. Ecotoxicol. Environ. Safety, 80: 339-348, http://dx.doi.org/10.1016/j. ecoenv.2012.04.002.

Manousaki E, Kalogerakis N. 2011. Halophytes present new opportunities in phytoremediation of heavy metals and saline soils. Ind. Eng. Chem. Res., 50(2): 656-660, http:// dx.doi.org/10.1021/ie100270x.

Mao T Y, Dai M X, Peng S T, Li G L. 2009. Temporal-spatial variation trend analysis of heavy metals $(\mathrm{Cu}, \mathrm{Zn}, \mathrm{Pb}, \mathrm{Cd}$, $\mathrm{Hg}$ ) in Bohai Bay in 10 Years. J. Tianjin Univ., (9): 817825. (in Chinese with English abstract)

Mendoza-Cózatl D G, Rodríguez-Zavala J S, RodríguezEnríquez S, Mendoza-Hernandez G, Briones-Gallardo R,
Moreno-Sánchez R. 2006. Phytochelatin-cadmiumsulfide high-molecular-mass complexes of Euglena gracilis. FEBS J., 273(24): 5 703-5 713, http://dx.doi.org/ 10.1111/j.1742-4658.2006.05558.x.

Nguyen-Deroche T L N, Caruso A, Le T T, Bui T V, Schoefs B, Tremblin G, Morant-Manceau A. 2012. Zinc affects differently growth, photosynthesis, antioxidant enzyme activities and phytochelatin synthase expression of four marine diatoms. Scientific World Journal, 2012: 982957 , http://dx.doi.org/10.1100/2012/982957.

Pandey N, Singh G K. 2012. Studies on antioxidative enzymes induced by cadmium in pea plants (Pisum sativum). $J$. Environ. Biol., 33(2): 201-206, http://www.ncbi.nlm.nih. gov/pubmed/23033681.

Ramos J, Naya L, Gay M, Abián J, Becana M. 2008. Functional characterization of an unusual phytochelatin synthase, LjPCS3, of Lotus japonicus. Plant Physiology, 148(1): 536-545, http://dx.doi.org/10.1104/pp.108.121715.

Rea P A. 2006. Phytochelatin synthase, papain's cousin, in stereo. Proc. Natl. Acad. Sci. USA, 103(3): 507-508, http://dx.doi.org/10.1104/pp.104.048579.

Romanyuk N D, Rigden D J, Vatamaniuk O K, Lang A, Cahoon R E, Jez J M, Rea P A. 2006. Mutagenic definition of a papain-like catalytic triad, sufficiency of the $\mathrm{N}$-terminal domain for single-site core catalytic enzyme acylation, and C-terminal domain for augmentative metal activation of a eukaryotic phytochelatin synthase. Plant Physiology, 141(3): 858-869, http://www.ncbi.nlm.nih. gov/pubmed/16714405.

Ruotolo R, Peracchi A, Bolchi A, Infusini G, Amoresano A, Ottonello S. 2004. Domain organization of phytochelatin synthase: functional properties of truncated enzyme species identified by limited proteolysis. J. Biol. Chem., 279(15): 14 686-14 693, http://dx.doi.org/10.1074/jbc. M314325200.

Taji T, Komatsu K, Katori T, Kawasaki Y, Sakata Y, Tanaka S, Kobayashi M, Toyoda A, Seki M, Shinozaki K. 2010. Comparative genomic analysis of 1047 completely sequenced cDNAs from an Arabidopsis-related model halophyte, Thellungiella halophila. BMC Plant Biology, 10(1): 261, http://dx.doi.org/10.1186/1471-2229-10-261.

Tamura K, Dudley J, Nei M, Kumar S. 2007. MEGA4: molecular evolutionary genetics analysis (MEGA) software version 4.0. Mol. Biol. Evol., 24(8): 1 596-1 599, http://dx.doi.org/10.1093/molbev/msm092.

Tsuji N, Hirayanagi N, Okada M, Miyasaka H, Hirata K, Zenk M H, Miyamoto K. 2002. Enhancement of tolerance to heavy metals and oxidative stress in Dunaliella tertiolecta by Zn-induced phytochelatin synthesis. Biochemical and Biophysical Research Communications, 293(1): 653-659, http://dx.doi.org/10.1016/S0006-291X(02)00265-6.

Vatamaniuk O K, Mari S, Lu Y P, Rea P A. 1999. AtPCS1, a phytochelatin synthase from Arabidopsis: isolation and in vitro reconstitution. Proc. Natl. Acad. Sci. USA, 96(12): 7 110-7 115, http://www.ncbi.nlm.nih.gov/pmc/articles/ PMC22073/pdf/pq007110.pdf.

Vestergaard M, Matsumoto S, Nishikori S, Shiraki K, Hirata 
K, Takagi M. 2008. Chelation of cadmium ions by phytochelatin synthase: role of the cysteine-rich C-terminal. Analytical Sciences, 24(2): 277-281, http:// www.ncbi.nlm.nih.gov/pubmed/18270423.

Wang H C, Wu J S, Chia J C, Yang C C, Wu Y J, Juang R H. 2009. Phytochelatin synthase is regulated by protein phosphorylation at a threonine residue near its catalytic site. J. Agric. Food Chem., 57(16): 7 348-7 355, http:// dx.doi.org/10.1021/jf9020152.

Wu H F, Liu X L, Zhao J M, Yu J B. 2012. Toxicological responses in halophyte Suaeda salsa to mercury under environmentally relevant salinity. Ecotoxicol. Environ. Safety, 85: 64-71, http://dx.doi.org/10.1016/j.ecoenv.2012. 03.016.

Xu J, Yin H X, Liu X J, Li X. 2010. Salt affects plant Cd-stress responses by modulating growth and $\mathrm{Cd}$ accumulation. Planta, 231(2): 449-459, http://dx.doi.org/10.1007/s00425009-1070-8.

Zhang X L. 2001. Investigation of pollution of $\mathrm{Pb}, \mathrm{Cd}, \mathrm{Hg}$, As in sea water and deposit of Bohai Sea area. Heilongjiang Environ. J., 25(3): 87-90. (in Chinese with English abstract)

Zhou M J, Yan T. 1997. Progress in marine eco-toxicology study in China. Res. Environ. Sci., 10(3): 1-6. (in Chinese with English abstract)

Zhu M H, Ding Y S, Zheng D C, Tao P, Ji Y X, Cui Y, Gong W M, Ding D W. 2005. Accumulation and tolerance of $\mathrm{Cu}$, $\mathrm{Zn}, \mathrm{Pb}$ and $\mathrm{Cd}$ in plant Suaeda heteroptera Kitag in tideland. Marine Environmental Science, 24(2): 13-16, http://europepmc.org/abstract/CBA/599367. 